\title{
Efeito da competitividade e da governança corporativa no nível de intangibilidade das companhias familiares
}

\author{
AntorioRodiguesAlbuquerqueFlho Mestrando em Administração e Controladoria. Universidade Federal do Ceará (UFC) - Brasil. \\ antoniofilhoufc@hotmail.com
}

\section{RESUMO}

Este estudo teve por objetivo analisar o efeito da competitividade e da governança corporativa no nível de intangibilidade das companhias abertas familiares listadas na Brasil Bolsa Balcão (B3). De cunho descritivo e abordagem quantitativa, a pesquisa utilizou a Regressão Linear Múltipla para analisar os dados em uma amostra que compreendeu 154 companhias. Averiguou-se a competitividade por meio do índice de Herfindahl-Hirschman $(\mathrm{HHI})$ e a governança corporativa através de uma variável proxy representada pelo Índice de Ações com Governança Corporativa Diferenciada (IGCX) da B3. O período de análise correspondeu ao intervalo entre os anos de 2010 a 2015. Os resultados do primeiro modelo demonstraram que a competitividade e o tamanho da empresa afetam positivamente o nível de intangibilidade das organizações, enquanto o crescimento não se apresentou como significante estatisticamente. Quanto ao segundo modelo, a governança corporativa e o tamanho da empresa associam-se positivamente com o nível de intangibilidade, ao passo que o crescimento não apresentou impacto sobre a intangibilidade. Ao final, conclui-se que, para conseguir maior nível de intangibilidade, as empresas buscam melhorar sua imagem por meio da adoção de uma melhor governança corporativa, e pela sua inserção em mercados mais competitivos.

Palavras-chave: Intangibilidade. Competitividade. Governança corporativa.

\section{Effect of competitiveness and corporate governance on the intangibility of family companies}

\begin{abstract}
This study aimed to analyze the effect of competitiveness and corporate governance on the level of intangibility of family companies listed in Brazil Bolsa Balcão (B3). It is of a descriptive and quantitative approach and used Multiple Linear Regression to analyze the data in a sample that comprised 154 companies. Competitiveness was assessed through the Herfindahl-Hirschman Index (HHI) and corporate governance through a proxy variable represented by the B3 Differentiated Corporate Governance Stock Index (IGCX). The analysis period corresponded to the interval between the years 2010 to 2015. The results of the first model showed that the competitiveness and the size of the company positively affect the level of intangibility of the organizations, whereas the growth did not present itself as statistically significant. As for the second model, corporate governance and company size are positively associated with the level of intangibility, while growth has no impact on intangibility. The results of the research indicate that, in order to achieve a higher level of intangibility, companies seek to improve their image through the adoption of better corporate governance and their insertion in more competitive markets.
\end{abstract}

Keywords: Intangibility. Competitiveness. Corporate governance. 


\section{INTRODUÇÃO}

No processo constante de evolução dos mercados, não há dúvidas que as empresas precisam dispor de um perfil diferenciado, e para isso, precisam buscar mecanismos que proporcionem capacidade e eficiência para criar, expandir e aplicar recursos (Moura, 2011). Dessa maneira, as empresas não podem limitar-se apenas aos recursos materiais, uma vez que a possibilidade de obtenção desses recursos pelas empresas concorrentes é maior (Machado \& Famá, 2011; Moura, Mecking \& Scarpin, 2013). Nesta perspectiva, companhias que apresentam diferenciais competitivos estarão mais propensas a atrair potenciais investidores (Pires, 2017), contribuindo positivamente para o aumento de valor da organização (Barajas, Shakina \& Fernandez, 2017).

Autores como Sveiby (1998), Lev (2001), Perez e Fáma (2006), Moura (2011), Decker (2013), Tsai, Lu, Hung e Yen (2016) e Appelbaum, Calla, Desautels e Hasan (2017) apontam o papel destacado pelos ativos intangíveis como vetores de vantagem competitiva e geradores de valor no cenário corporativo, demonstrando que tais ativos representam um diferencial competitivo para as organizações.

Com a atuação conjunta e eficiente dos ativos tangíveis e intangíveis, as empresas estão sujeitas a possuir maior competitividade (Perez \& Famá, 2006). Consoante, Teixeira, Pacheco, Hexsel e Castagno Junior (2005) as empresas precisam dispor de um conjunto de ativos, tanto tangíveis quanto intangíveis, que se integrem e possibilitem a melhoria contínua. Nesse contexto, infere-se que uma parte do valor da empresa pode ser representada pelos seus recursos intangíveis, considerados vetores de vantagem competitiva que agregarão na geração de riqueza das empresas.

Conforme Moura et al. (2013) para a obtenção de maior competividade, as empresas devem apresentar níveis significativos de ativos intangíveis, pois esses ativos proporcionam vantagens competitivas com relação aos demais participantes do mercado, confirmando a essencialidade dos mesmos.

As boas práticas de governança corporativa também são relevantes no ambiente corporativo (Moura, 2011). De acordo com o Código de melhores práticas de governança corporativa do Instituto Brasileiro de Governança Corporativa [IBGC] (2015) cabe à administração a obrigação de divulgar e cultivar informações não somente do desempenho econômico-financeiro, mas também, de outros fatores (por exemplo, os intangíveis) que conduzem a criação de valor no âmbito empresarial.

Além das melhores práticas de governança corporativa para a condução da evidenciação de informações de ativos intangíveis, Kent e Stwart (2008) apontaram em seus estudos que, o reconhecimento e mensuração dos ativos intangíveis são influenciados pela governança corporativa, pois esta contribui para o correto cumprimento das regulamentações contábeis, além de monitorar a aquisição de novos intangíveis.

Ante 0 exposto, apresenta-se 0 crescente destaque dos ativos intangíveis como assunto relevante no ambiente empresarial e científico (Kayo, 2002). Além do que, as informações sobre os ativos intangíveis são fundamentais para os diversos stakeholders, que em contrapartida investem seus recursos nas empresas que melhor se destacam no mercado (Rolim, 2009). Compartilhando do mesmo pensamento, Moura (2011) ressalta que para a realização dessa condição, a adoção de melhores práticas de governança é fator proeminente para maior evidenciação dos intangíveis.

Destarte, diante da deferência que a temática apresenta no ambiente de negócios, surgiu a seguinte pergunta da pesquisa: Qual o efeito da competitividade e da governança corporativa no nível de intangibilidade das companhias abertas familiares listadas na Brasil Bolsa Balcão (B3)? Nesta perspectiva, o estudo traçou como objetivo geral averiguar o efeito da competitividade e da governança corporativa no nível de intangibilidade das companhias abertas familiares listadas na Brasil Bolsa Balcão (B3).

A justificativa para realização desse estudo decorre da importância dos intangíveis como propulsores de maior competitividade (Moura et al., 2013), criação de valor e desempenho (Marin, Liszbinski \& Kronbauer, 2015; Maia \& Vasconcelos, 2016; Silva, Sousa \& Klann, 2017). Também, pela adoção de melhoras práticas de governança corporativa, que segundo Machado e Famá (2011) possui ligação positiva com os intangíveis, uma vez que, as empresas passam a preocupar-se com o reconhecimento e mensuração desse grupo de ativos, bem como a aquisição de novos investimentos intangíveis.

Ademais, infere-se a carência de pesquisas que relacionem tais temáticas com a intangibilidade das empresas. Assim, como a governança corporativa contribuem com a melhoria da imagem de uma organização 
(Keean \& Alggestan, 2001; Machado \& Famá, 2011), espera-se que esta apresente relevância proeminente na formação de ativos intangíveis. Outrossim, aponta-se também, que empresas situadas em ambientes altamente competitivos (competitividade de mercado) estão propensas a obter uma maior proporção de ativos intangíveis (Moura et al., 2013).

\section{REFERENCIAL TEÓRICO}

Esta seção traz os posicionamentos teóricos e empíricos que serviram de base para 0 desenvolvimento da linha de raciocínio da pesquisa. Inicialmente, apresentam-se ponderações sobre a intangibilidade. Na sequência, trazem-se informações sobre a competitividade empresarial e, por último, so bre a governança corporativa.

\subsection{Intangibilidade}

Os ativos intangíveis são recursos importantes no cenário empresarial, conforme pode ser verificado em estudos como os de Barney (1991), Lev (2001), Perez e Fáma (2006), Leite e Santos (2013), Marin, Liszbinski e Kronbauer (2015), Tsai et al. (2016) e Appelbaum et al. (2017). De acordo com Appelbaum et al. (2017) 0 reconhecimento de diferentes tipos de intangíveis é relevante, dentre outros, por reforçar a agilidade das organizações, fazendo com que reajam de forma mais rápida e apropriada às mudanças imprevisíveis.

Assim, conforme a Teoria da Visão Baseada em Recursos (VBR) "os recursos devem ser distribuídos de forma heterogênea entre as firmas; aqueles que são específicos, raros, e de difícil imitação têm potencial para promover o desempenho superior e sustentável" (Carvalho, Kayo \& Martin, 2010, p. 886). Assim, nota-se que tais características corroboram com as qualidades dos recursos intangíveis que são considerados como vetores de diferencial competitivo advindos de seus atributos raros, valiosos, inimitáveis e insubstituíveis (Albuquerque Filho et al., 2018).

A relevância dos intangíveis no cenário acadêmico e empresarial ganhou importância pelo diferencial competitivo conferido aos seus possuidores (Tsai et al., 2016; Appelbaum et al., 2017). Embora a mensuração, estimação e reconhecimento desse grupo de ativo seja bastante complexo (Hendriksen \& Van Breda, 1999; Albuquerque Filho et al., 2018), a sua importância como elemento estratégico é fundamental para o sucesso corporativo das organizações (Clausen \& Hirth, 2016; Barajas et al., 2017).

Para o Pronunciamento Técnico, Comitê de Pronunciamentos Contábeis [CPC 04] (R1, 2010), "os intangíveis são recursos não monetários, sem existência corpórea, mas identificáveis que sejam controláveis pela empresa e que gerarão benefícios econômicos (fluxo de caixa)". Tal definição confirma também os pressupostos destacados por Lev (2001), Schmidt e Santos (2002), Martins (2002), Milone (2004), Machado e Famá (2011), Decker et al. (2013), Leite e Santos (2013), Pires (2017) sobre os intangíveis.

Lev (2001) destaca que o fato gerador é que determina a classificação do ativo intangível, sendo classificados em três grupos: "(1) inovação; (2) recursos humanos; e (3) desenhos organizacionais." Kayo (2002) por sua vez, classifica tais ativos em: ativos humanos, de inovação, estruturais e de relacionamento.

Quanto à sua mensuração, Hendriksen e Van Breda (1999) compartilha a dificuldade de se medir os intangíveis, quando não são identificáveis ou separáveis. Portanto, segundo os autores, a entidade pode optar, em algumas circunstâncias, pelo método de custo ou pelo método de reavaliação, desde que este último não esteja restringido por lei ou norma legal.

Para o reconhecimento de um intangível como ativo, conforme Hendriksen e Van Breda (1999); Martins (2002); Schmidt, Santos e Fernandes (2006) é essencial considerar a questão da identificação. De acordo com Moura (2011), a identificação desses ativos requer que os mesmos sejam separáveis da empresa, para que sejam passíveis de venda, em caso de negociações no mercado.

O CPC 04 (R1, 2010) destaca que os intangíveis exigem do is critérios de reconhecimento: a) os futuros benefícios econômicos esperados, a favor da organização, devem ser comprovados; b) o custo do ativo deve ser mensurado com confiabilidade. 
Ressalta-se então que, a importância conferida aos intangíveis é fundamental para orientar os investidores na avaliação das oportunidades de investimento de forma a decidir a melhor forma de alocar seu aporte de recursos dentre as diversas opções disponíveis no mercado (Bushman \& Smith, 2003).

\subsection{Competitividade}

As mudanças ocorridas no cenário empresarial obrigaram as empresas a formularem estratégias que Ihes confiram maior competitividade, e para isso, a sobrevivência das mesmas requer padrões de conduta que Ihes proporcionem diferenciais competitivos em seu meio de ação (Perez \& Famá, 2015). Ressalta-se também que as companhias se destacam competitivamente quando adquirem resultados satisfatórios a partir das práticas aceitas e valorizadas no ambiente em que atuam, motivo pelo qual muitas procuram se referenciar nos exemplos de sucesso (Caldeira, 2007).

A competitividade configura a comparação entre os participantes do mesmo ambiente de atuação que determinarão seu conceito e as formas de avaliá-las (Hinings \& Greenwood, 1989). Nesse sentido, Caldeira (2007) destaca que a competitividade confere a seus possuidores maior eficiência e produtividade e é medida através de indicadores de inserção no mercado empresarial internacional, assim como por meio de medidas de eficiência na utilização de recursos (ativos intangíveis), tais como indicadores de crescimento, retorno de capital, bem como investimento em tecnologia.

Propulsores do mesmo pensamento, Calmanovici (2011) e Kupfer e Hasenclever (2013) descrevem a competitividade como a eficiência atingida pelas companhias na competição, pois reflete a capacidade de distinguir-se dos seus concorrentes. Autores como Possas (1993), ressaltam a relevância desse conceito de competitividade com destaque para definição e implementação de aumento de capitais, desde que auxiliado por vantagens competitivas com maior ou menor eficácia em meios a seus concorrentes.

As mudanças ocorridas no cenário empresarial obrigam as empresas a formularem estratégias que Ihes confiram maior competitividade, e para isso, sobrevivência das mesmas requer padrões de conduta que Ihes proporcionem diferenciais competitivos em seu meio de ação (Perez \& Famá, 2015). Ressalta-se também que as companhias se destacam competitivamente quando adquirem resultados satisfatórios a partir das práticas aceitas e valorizadas no ambiente em que atuam, motivo pelo qual muitas procuram se referenciar nos exemplos de sucesso (Caldeira, 2007).

Coutinho (1994), Ferraz (1997) e Kupfer e Hasenclever (2013) apresentam alguns fatores que são determinantes da competitividade que influenciam a empresa no ambiente empresarial, são eles: suas próprias características (fator interno), o mercado em que atua (fator estrutural) e 0 ambiente concorrencial (fator sistêmico).

Para Ribeiro (2009), as empresas precisam adotar novas formas de geração de valor, que valorizem a flexibilidade, velocidade, inovação, integração, e para isso, os ativos intangíveis tornam-se fundamentais.

Teixeira et al. (2005) ressalta a preponderância desses intangíveis, destacando que marcas, processo produtivo, gestão interna, relacionamento com clientes e conhecimento são potenciais competitivos que uma organização pode possuir. Para Grant (1991), tais recursos intangíveis são a base para a lucratividade da empresa.

Portanto, a tentativa de replicação desse conjunto de ativos confere às organizações diferenciais competitivos com relação as suas concorrentes e que consequentemente, em ambientes altamente competitivos, os intangíveis tornam-se mais representativos (Moura et al., 2013).

Isto posto, destaca-se a primeira hipótese desse estudo:

$\mathbf{H}_{1}$ : A competitividade se relaciona positivamente com o nível de intangibilidade das empresas.

\subsection{Governança Corporativa}

A governança corporativa está atrelada um sistema integrado de práticas administrativas que abrange o controle interno e externo, destacando-se pela busca premente em harmonizar a relação entre gestores e acionistas (Darosi, 2014). 
Silveira (2004), Andrade e Rossetti (2004) e Santos (2009) descrevem que a proteção dos acionistas minoritários, assim como dos demais stakeholders envolvidos com a empresa cabem às práticas de governança corporativa, uma vez que possuem como objetivo principal garantir maior transparência no processo de tomada de decisões pelos gestores e proporcionar garantia de participação aos demais envolvidos, o que acaba refletindo na imagem na empresa no ambiente corporativo.

A governança corporativa, de acordo com o código de melhores práticas de governança corporativa - IBCG (2015), procura criar mecanismos eficientes, de incentivo e monitoramento, com o propósito de providenciar a boa relação entre sócios e acionistas a fim de evitar o conflito de agência.

Nesta linha de raciocínio, Oliveira (2006) destaca que a governança corporativa abrange formas de atuação, procedimentos ou processos estabelecidos pela organização, ou seja, um conjunto de práticas administrativas que visam otimizar o desempenho da empresa. 0 autor confirma a papel proeminente da governança corporativa como promotora de maior transparência e facilidade ao acesso de informações básicas da empresa, contribuindo dessa forma com um modelo de gestão mais eficaz.

Assim, o IBGC pondera que os princípios que norteiam, em maior ou menor grau, as práticas de governança corporativa é a transparência, a equidade, a prestação de contas e a responsabilidade corporativa (IBCG, 2015). Nesse interim, como evidenciado por Moura (2011), as companhias que adotam boas práticas de governança corporativa tendem a proporcionar maior segurança aos investidores.

O IBCG (2015) descreve também que as boas práticas de governança corporativa têm por finalidade beneficiar as empresas aumentando seu valor perante a sociedade, contribuindo para sua perenidade, além de facilitar seu acesso ao capital. Além disso, Silveira (2006) mencionam que as boas práticas de governança corporativa conduzem a tomada de decisões de acordo com os interesses da companhia e de seus acionistas.

Há evidências na literatura de que melhores práticas de governança corporativa conduzem a obtenção de uma melhor e maior evidenciação dos ativos intangíveis. Kent e Stewart (2008) destacam que o reconhecimento e a mensuração dos ativos intangíveis são influenciados pela governança corporativa, pois esta contribui para o correto cumprimento das regulamentações contábeis, além de monitorar a aquisição de novos intangíveis (Kenn \& Alggestan, 2001). Nessa perspectiva, Machado e Famá (2011) destacam que as companhias que adotam boas práticas de governança corporativa aumentam a probabilidade de obtenção de ativos intangíveis, contemplando a proposição que existe uma forte ligação entre ambos.

Outrossim, empresas que apresentam altos níveis de ativos intangíveis registrados em seus demonstrativos, de acordo com Himmelberg, Hubbard e Palia (1999), tendem a apresentar maiores necessidades em adotar boas práticas de governança corporativa do que as companhias com maiores proporções em ativos tangíveis.

Assim, pressupõe-se a segunda hipótese do estudo:

$\mathbf{H}_{2}$ : A governança corporativa se relaciona positivamente com 0 nível de intangibilidade das empresas.

\section{PROCEDIMENTOS METODOLÓGICOS}

Esta pesquisa, caracterizada como descritiva, foi realizada por meio de análise documental e abordagem quantitativa dos dados. A população é composta pelas companhias abertas familiares listadas na Brasil Bolsa Balcão (B3), sendo que aquelas que realizavam atividades financeiras e as que não tinham informações necessárias sobre a competitividade, governança corporativa e intangibilidade foram excluídas do estudo.

A B3 é uma das principais empresas de infraestrutura de mercado financeiro no mundo, com atuação em ambiente de bolsa e de balcão e que resultou da fusão entre a BM\&FBovespa e a Cetip. Dessa forma, assim como os estudos realizados por Albuquerque Filho et al. (2018), Marin, Liszbinski \& Kronbauer (2015), Moura (2011) e Moura et al. (2013), a população do estudo correspondeu as empresas listadas na B3.

Para identificar as companhias familiares, que correspondem à amostra do estudo, utilizou-se a metodologia de La Porta, Lopez de Silanes e Shleifer (1999), que rastreou a cadeia de propriedade até identificar o último acionista controlador. Consideraram como último acionista controlador aquele que, de 
forma direta ou indireta, possuía o controle da empresa da amostra pesquisada. Foi considerada como familiar qualquer empresa em que uma família ou um indivíduo era o proprietário final (em termos de direitos de voto), com participação mínima de $10 \%$. Após estes procedimentos, a amostra de pesquisa analisada foi composta por 154 companhias abertas familiares, de um total de 485 empresas que estavam listadas na B3.

No que concerne aos objetivos, esta pesquisa classifica-se como descritiva. Richardson et al. (1999, p.146), possui "o propósito de fazer afirmaçoes para descrever aspectos de uma população ou analisar a distribuição de determinadas características ou atributos". Esta pesquisa buscou analisar a influência da competitividade e da governança corporativa em relação ao nível de intangibilidade das companhias abertas familiares listadas na B3.

Quanto aos procedimentos, a pesquisa classifica-se como documental. Marconi e Lakatos, 2002, p. 62 destacam que "[...] a característica da pesquisa documental é que a fonte de coleta de dados está restrita a documentos, escritos ou não, constituindo o que se denomina de fontes primárias. Estas podem ser recolhidas no momento em que o fato ou fenômeno ocorre, ou depois".

Neste estudo, foram utilizadas informações constantes no sítio da B3. Do balanço patrimonial foram retirados os valores do ativo intangível, do sítio da B3 retirou-se a informação sobre a governança corporativa, além do que os valores correspondentes à competitividade, patrimônio líquido, crescimento e tamanho da empresa foram selecionados por meio da Economática, referentes ao período de 2010 a 2015.

Quanto à abordagem, este estudo enquadra-se como quantitativo. Richardson, 1999, p. 29 destaca que a abordagem quantitativa "[...] caracteriza-se pelo emprego da quantificação tanto nas modalidades de coleta de informações, quanto no tratamento dessas através de técnicas estatísticas desde as mais simples, às mais complexas, como coeficiente de correlação, análise de regressão etc. [...]". Para atingiro objetivo, utilizouse de estatísticas descritivas e regressão linear múltipla.

No Quadro 1, é possível observar as variáveis utilizadas na pesquisa.

\begin{tabular}{|c|c|c|}
\hline \multicolumn{3}{|c|}{ Variável Dependente } \\
\hline Grupo de Indicadores & Indicadores & Autores base \\
\hline Intangibilidade (INTANG) & $\begin{array}{c}\text { Grau de intangibilidade }(\mathrm{GI})= \\
\text { razão entre o valor de mercado } \\
\text { total das ações e o patrimônio } \\
\text { líquido contábil }\end{array}$ & $\begin{array}{l}\text { Lev (2001), Kayo e Famá (2004); Perez e } \\
\text { Famá (2009); Machado e Famá (2011); } \\
\text { Nascimento et al. (2012); Kreuzberg, Rigo } \\
\text { e Klann (2013);_Decker et al. (2013). }\end{array}$ \\
\hline \multicolumn{3}{|c|}{ Variáveis Independentes } \\
\hline Competitividade (COMPET) & Índice de Herfindal-Hirschman & $\begin{array}{c}\text { Dhaliwalet al. (2008), Giroud e Mueller } \\
\text { (2010), Almeida (2010) e Moura, Mecking } \\
\text { e Scarpin (2013). }\end{array}$ \\
\hline $\begin{array}{l}\text { Governança Corporativa } \\
\text { (GC) }\end{array}$ & $\begin{array}{c}\text { Variável dummy. } \\
\text { Listada no IGCX =1 } \\
\text { Não listada no IGCX =0 }\end{array}$ & $\begin{array}{l}\text { Martinez (2011); Barros, Soares e Lima } \\
\text { (2013); Mazzioni et al. (2015). }\end{array}$ \\
\hline \multicolumn{3}{|c|}{ Variáveis de Controle } \\
\hline Crescimento (CRESC) & Crescimento do ativo total & Kayo et al. (2006). \\
\hline Tamanho (TAM) & Logaritmo do ativo total & Kayo et al. (2006). \\
\hline
\end{tabular}

Quadro 1. Listagem das variáveis dependentes e independentes utilizadas na pesquisa

Fonte: Elaborada pelo autor (2019).

Nota-se, no Quadro 1 que a proxy utilizada para a variável governança corporativa foi o Índice de Ações com Governança Corporativa Diferenciada (IGCX) da B3. De acordo com a B3 (2017) o IGCX é um índice que [...] "tem por objetivo medir o desempenho de uma carteira teórica composta por ações de empresas que apresentem bons níveis de governança corporativa". Tais empresas devem ser negociadas no Novo Mercado ou estar classificadas nos Níveis 1 ou 2 da B3. Então, criou-se uma variável categórica que recebeu valor "1" quando a empresa da amostra estava listada no IGCX e "0" caso contrário. 
Calculou-se também a competitividade de mercado, cuja proxy utilizada foi o índice de HerfindahlHirschman (HHI), que mensura a concentração de mercado por meio da soma dos quadrados das parcelas (marketshare) de cada empresa, o que possibilita caracterizar o tipo de concorrência em que tais empresas se encontram (LIJ ESEN, 2004).

A avaliação da competitividade, por meio do índice $\mathrm{HHI}$ já foi realizada por outros pesquisadores, tais como Dhaliwal (2008), Giroud e Mueller (2010), Almeida (2010) e Moura et al. (2013), em que o índice é calculado pela seguinte equação:

$$
\mathrm{HHI}=\sum_{i=1}^{n} \beta_{i}^{2}
$$

Em que $\beta$ i representa o percentual do ativo total da empresa em relação ao total da amostra. Assim como nos estudos de Giroud e Mueller (2010) e Almeida (2010), Moura et al. (2013) optou-se por utilizar valores de ativo total ao invés do total de vendas, pois, conforme apontam esses autores, 0 ativo total tem menor oscilação no decorrer dos períodos e captura outras características, como tamanho e ativos controlados pelas companhias.

É possível perceber ainda, no Quadro 1, dentre as variáveis de controle, que o tamanho foi medido por meio do logaritmo natural do valor contábil dos ativos totais das empresas e a variável crescimento referese ao crescimento do ativo total no decorrer do ano.

O período escolhido para a análise será o intervalo compreendido entre os anos de 2010 a 2015, visto que, a divulgação efetiva dos ativos intangíveis deu-se a partir do ano de 2010. A análise dos dados até 0 ano de 2015 se deu pela disponibilidade limitada das informações dos construtos pela maioria das empresas que compõem a amostra. Apesar disso, Moura (2011) destaca que a governança corporativa e a obtenção de recursos pelas empresas requerem investimentos e planejamento a longo prazo, o que não prejudica a análise dos resultados. A amostra final correspondeu a 154 empresas que detinham todos os dados disponíveis para a realização da pesquisa.

Dessa forma os dois modelos econométricos deste estudo consistem:

$I N T A N G i j=\beta 0+\beta 1 C O M P E T i j+\beta 2 C R E S C_{i j}+\beta 3 T A M i j+u i j(1)$

INTANG $i j=\beta 0+\beta 1 G C_{i j}+\beta 2 C R E S C_{i j}+\beta 3 T A M i j+u i j(2)$

Em que:

INTANG representa o nível de intangibilidade das empresas;

COMPET corresponde à competitividade da empresa;

GCrepresenta a governança corporativa;

CRES (crescimento) e TAM (tamanho);

$\beta 0$ é o intercepto;

euijé o termo de erro estocástico da regressão em painel.

Ressalta-se que foram observados os pressupostos da regressão linear múltipla para a consecução da análise dos resultados como a normalidade dos resíduos, verificada por meio do teste de KolmogorovSmirnov; a multicolinearidade por meio do fator de inflação de variância - VIF e Tolerance, a fim de identificar se existe relações lineares entre a variável dependente com as independentes de uma regressão; a homocedasticidade, por meio do teste de Pesarán-Pesarán para verificar se a variância do termo de erro é constante; e a ausência de autocorrelação serial, por meio do teste de Durbin-Watson, com o intuito de verificar se o termo de erro é não autocorrelacionado.

\section{DESCRIÇÃO E ANÁLISE DOS RESULTADOS}

Esta seção contempla a apresentação e análise dos resultados obtidos. Primeiramente, apresenta-se a análise descritiva das variáveis da pesquisa. Na sequência, traz-se a análise da regressão dos coeficientes da 
equação da influência da competitividade sobre a intangibilidade. Por último, apresentam-se os resultados da regressão linear múltipla que possibilitou verificar a influência da governança corporativa sobre a intangibilidade.

Na Tabela 1 é possível observar as médias das variáveis da pesquisa, ao longo dos anos de 2010 a 2015.

\begin{tabular}{c|c|c|c|c|c|c}
\hline \multirow{2}{*}{ Variáveis } & \multicolumn{7}{|c}{ Média ao longo dos anos } \\
\cline { 2 - 7 } & $\mathbf{2 0 1 0}$ & $\mathbf{2 0 1 1}$ & $\mathbf{2 0 1 2}$ & $\mathbf{2 0 1 3}$ & $\mathbf{2 0 1 4}$ & $\mathbf{2 0 1 5}$ \\
\hline Intangibilidade & 7,2063 & 7,3267 & 6,3382 & 8,1291 & 6,8853 & 6,4169 \\
Competitividade & 0,0178 & 0,0171 & 0,0212 & 0,0246 & 0,0196 & 0,0396 \\
Governança & 0,3506 & 0,3506 & 0,3506 & 0,3506 & 0,3506 & 0,3506 \\
corporativa & 6,0031 & 19,3004 & 4916,1190 & 4916,1190 & 6,6576 & 3,9697 \\
Crescimento & 259,7917 & 6,0608 & 6,1110 & 5,7829 & 6,1295 & 6,1345 \\
Tamanho & 2506
\end{tabular}

Tabela 1. Estatística descritiva das variáveis da pesquisa (2010 a 2015)

Fonte: Elaborada pelo autor (2019).

Nota-se na tabela 2 que no ano de 2010, a variável que mais se destacou foi o tamanho, com nível médio equivalente a 259,7917, demonstrando que 0 ativo total das empresas teve aumento ascendente durante 0 ano, fato comprovado pelo aumento evidente do total do ativo, tanto através de ativos físicos como de ativos intangíveis.

Também se apresentou positivamente, em 2010, as variáveis intangibilidade e crescimento, com representatividade de 7,2063 e 6,0031, respectivamente. Em contrapartida, o nível de governança corporativa e competitividade evidenciad os pelas empresas durante 0 ano, foi baixo e equivalente a 0,3506 e 0,0178, nesta ordem, refletindo a necessidade premente de maior evidenciação desses valores por essas empresas, uma vez que, autores como Tavares (2007) e Kupfer e Hasenclever (2013) descrevem a competitividade como a eficiência atingida pelas companhias na competição, pois reflete a capacidade de distinguir-se dos seus concorrentes. Além do que, como pondera Moura (2011), as companhias que adotam boas práticas de governança corporativa refletirão maior segurança aos investidores.

No ano de 2011, a variável crescimento foi relevante, com um valor correspondente a 19,3004, seguida pela intangibilidade e tamanho, apresentando registros equivalentes a 7,3267 e 6,0608, respectivamente. Em menores níveis, destacaram-se a governança corporativa e a competitividade, refletindo que não houve evolução com relação ao ano anterior.

Quanto ao ano de 2012, a variável crescimento continuou sendo o proeminente, apresentando um incremento significativo de 4896,8186 com relação ao ano anterior. Nesse ano, destaca-se também o nível de intangibilidade das empresas, que registrou um valor correspondente a 6,3382, que embora menor que os anos de 2010 e 2011, demonstra a importância dada aos ativos intangíveis a partir da harmonização das normas brasileiras aos padrões internacionais de contabilidade, uma vez que os investidores passaram a valorizar a inserção desse tipo de ativo nos demonstrativos da empresa. Desfavoravelmente, destacaram-se as variáveis governança corporativa $(0,3506)$ e a competitividade $(0,0212)$.

Ainda na tabela 1, com relação ao ano de 2013, destacou-se a variável crescimento, apresentando o mesmo montante que 0 ano anterior, seguida pela intangibilidade, que apresentou seu maior nível desde 2010, acompanhada também pelo tamanho, que desfavoravelmente apresentou seu menor valor, correspondente a 5,7829. Ao passo que a variável governança corporativa $(0,3506)$ e competitividade $(0,0246)$ registraram os níveis mais baixos.

Em 2014, a intangibilidade destaca-se na liderança, apresentando um nível de 6,8853, porém com um decréscimo de 1,2438 com relação ao ano anterior. Na segunda posição encontra-se 0 crescimento, apresentando um declínio bastante significativo, com redução de 4909,4614 em seu nível médio. Verificou-se também que o tamanho da empresa apresentou destaque de 6,1295, demonstrando um aumento com relação 
ao ano antecessor de 0,3466 em seu montante médio. Destacaram-se também a governança corporativa e a competitividade, com os valores mais baixos, assim como nos anos anteriores.

Em relação ao ano de 2015, apesar das oscilações de quedas e aumentos no montante médio das variáveis, destacou-se a intangibilidade que se manteve em equilíbrio com média 6,4169. A variável competitividade, embora apresentando os valores mais baixos da amostra durante os anos analisados, vem incrementando seu montante, mesmo que em níveis bem pequenos.

De modo geral, percebeu-se que a variável que mais se destacou durante os anos analisados, com maiores níveis médios foi à intangibilidade, embora não se destacando na liderança em todos os anos. Tal concepção mostra que no decorrer dos anos, os investidores passaram a valorizar as organizações que apresentavam maiores níveis de intangíveis em seus registros, o que vai ao encontro do pensamento de Kayo et al. (2006), que destacam o aumento progressivo dos intangíveis quando o assunto é a geração de valor para as organizações.

É relevante destacar também que, a governança corporativa manteve-se constante durante o período analisado, mas se destacando como a segunda variável com montante mais baixo durante todos os anos, demonstrando a necessidade da adoção de melhores práticas de governança corporativa. Por fim, torna-se evidente a busca por maior eficiência e produtividade por parte das empresas, resultado esse refletido pelos níveis evidenciados pela competitividade durante o período analisado.

$\mathrm{Na}$ Tabela 2 apresentam-se os coeficientes da regressão, que possibilitam analisar o poder preditivo da competitividade sobre a intangibilidade das empresas da análise, no perío do de 2010 a 2015.

\begin{tabular}{c|c}
\hline Variáveis & $\begin{array}{c}\text { Intangibilidade } \\
\text { Coeficiente } \\
\text { (estatística-t) }\end{array}$ \\
\hline Constante & $-12,213^{*}$ \\
Competitividade & $-3,747$ \\
Crescimento & $\mathbf{0 , 5 1 0 *}$ \\
& $-0,107$ \\
Tamanho & $-1,022$ \\
& $-0,509$ \\
R'Ajustado & $\mathbf{3 , 2 0 *}$ \\
F-ANOVA & 5,96 \\
Durbin Watson & 0,35 \\
Pesarán-Pesarán & $\mathbf{1 2 , 2 7 *}$ \\
VIF/Tolerance & 1,65 \\
\hline
\end{tabular}

Tabela 2. Coeficientes da equação da influência da competitividade na intangibilidade (2010 a 2015) Fonte: Elaborada pelo autor (2019)

Nota: $*$ Significativo a 1\%** Significativo a 5\% *** Significativo a 10\%

É possível perceber na Tabela 2 que o $\mathrm{R}^{2}$ ajustado foi de apenas 35\%, demonstrando um poder explicativo baixo. Tal assertiva é similar ao registro encontrado em outras pesquisas correlatas, como as destacadas por Brighenti, Chiarello e Rosa (2014) e Camargo, Moura e Zanin (2016). No entanto, o teste FANOVA foi significante $(0,01)$, ou seja, o conjunto de variáveis independentes exerce influência sobre a variável dependente. Observa-se também que o resultado da estatística de Durbin-Watson demonstra que não há problemas de autocorrelação dos resíduos, já que o seu valor foi de 1,65, bem próximo de 2 .

0 teste de comportamento dos resíduos (Pesarán-Pesarán) demonstra que o pressuposto da homocedasticidade não foi violado. E, o fator de inflação de variância (VIF) e o Tolerance (fator diretamente relacionado com o valor de tolerância) apresentaram valores inferiores a 10. Portanto, nesse caso não há 
problema de multicolinearidade entre as variáveis independentes do modelo. Conforme Hair et al. (2005), um VIF é considerado alto quando está acima de dez.

Em relação aos coeficientes da regressão, é possível verificar na tabela 2 que a competitividade e 0 tamanho são estatisticamente significantes ao nível de $1 \%$. 0 coeficiente positivo de 0,510 da competitividade revela indícios de que empresas situadas em mercados competitivos ap resentam maior representatividade de ativos intangíveis em seu patrimônio corroborando com os achados de Moura et al. (2011) que evidenciaram que os recursos intangíveis das empresas são vetores de diferencial competitivo que podem agregar maior valor para as empresas (Albuquerque filho et al., 2018; Lev, 2001). Ademais, infere-se também que o tamanho revelou proporcionar maior intangibilidade (coef. 3,20), ou seja, quanto maior a empresa, maiores as chances de obter ativos intangíveis. Tal resultado corrobora com os achados de Kayo et al. (2006) que analisaram os possíveis determinantes econômico-financeiros da intangibilidade das empresas brasileiras e verificaram que a partir de determinado tamanho, a forma de a empresa crescer é através de investimento em ativos intangíveis, assim como nos estudos realizados por Brighenti, Chiarello e Rosa (2014) que investigaram a divulgação consolidadas de sete bancos portugueses e sete bancos espanhóis, no período de 2006 a 2009 e que encontraram resultados convergentes.

Em razão do coeficiente do crescimento não apresentar significância estatística, não é possível afirmar que maiores ou menores níveis de crescimento impacta no nível de intangibilidade das companhias da amostra. A Tabela 3 apresenta a regressão que trata da influência da governança corporativa sobre a intangibilidade das empresas, no período de 2010 a 2015.

\begin{tabular}{c|c}
\hline Variáveis & $\begin{array}{c}\text { Intangibilidade } \\
\text { Coeficiente } \\
\text { (estatística-t) }\end{array}$ \\
\hline Constante & $-12,698^{*}$ \\
Governança Corporativa & $-3,923$ \\
Crescimento & $\mathbf{1 , 8 6 4 ^ { * * * }}$ \\
& $-1,674$ \\
Tamanho & $-8,891$ \\
& $-0,440$ \\
R2Ajustado & $\mathbf{3 , 3 8 *}$ \\
F-ANOVA & 6,27 \\
Durbin Watson & 0,38 \\
Pesarán-Pesarán & $\mathbf{1 3 , 2 4 *}$ \\
VIF/Tolerance & 1,65 \\
\hline
\end{tabular}

Tabela 3. Coeficientes da equação da influência da governança corporativa na intangibilidade (2010 a 2015)

Fonte: Elaborada pelo autor (2019)

* Significativo a $1 \%,{ }^{* *}$ Significativo a $5 \%, * * *$ Significativo a $10 \%$

A análise da tabela 3 permite verificar que o $R^{2}$ ajustado foi de $38 \%$. Todavia, verifica-se que o teste $F$ ANOVA foi significante $(0,01)$, demostrando que o conjunto das variáveis independentes influencia a intangibilidade. 0 resultado da estatística de Durbin-Watson destaca que não há problemas de autocorrelação de resíduos, já que seu valor foi de 1,65. Destaca-se também que o pressuposto da homocedasticidade não foi violado, resultado refletido pelo teste de Pesarán- Pesarán.

Nota-se que o fator de inflação de variância (VIF) e o Tolerance apresentam valores menores que 10, ressaltando dessa forma a falta de multicolinearidade entre as variáveis independentes do modelo.

Em relação à governança corporativa, é possível verificar que esta apresentou significância estatística $(0,1)$, onde seu coeficiente positivo revela indícios de que quanto melhor a governança corporativa, maior o nível de intangibilidade registrado pelas organizações. Tal resultado corrobora com o encontrado nos estudos 
realizados por Silveira (2004) e Couto (2009), que mostraram que adoção de melhores práticas de governança é bem vista pelo mercado e isso reflete positivamente na valorização da organização, bem como na aquisição de novos intangíveis como descrevem Keean e Alggestan (2001), confirmando dessa forma a segunda hipótese desta pesquisa ( $\mathrm{H} 2)$.

Dentre as variáveis de controle, verifica-se que "tamanho" revelou-se estatisticamente significante ao nível de $1 \%$ e com coeficiente positivo $(3,38)$, indicando que quanto maior o tamanho da empresa, maior será o seu nível de intangibilidade que indica quantas vezes o valor de mercado é superior ao valor do patrimônio líquido (Grau de intangibilidade - GI). Este resultado coaduna em parte com Kayo et al. (2006). Para os autores, empresas maiores e com menos dívidas têm maior probabilidade de serem intangível-intensivas. Neste estudo, observa-se que empresas maiores tendem a apresentar maior grau de intangibilidade, que poderá resultar em maior valor de mercado das empresas

Em razão do coeficiente do crescimento não apresentar significância estatística, não é possível afirmar nada sobre seus impactos sobre a intangibilidade nas empresas.

\section{CONSIDERAÇÕES FINAIS}

O estudo objetivou averiguar o efeito da competitividade e da governança corporativa no nível de intangibilidade das companhias abertas familiares listadas na Brasil Bolsa Balcão (B3). Para tal, realizou-se pesquisa descritiva, conduzida por meio de análise documental e abordagem quantitativa dos dados, em uma amostra composta por 154 companhias.

Em relação à análise descritiva das variáveis do estudo, os resultados demonstraram que a variável crescimento se destacou de forma significativa durante os anos de 2011, 2012 e 2013, apresentando montantes cerca de 700 vezes maiores que os níveis médios das demais variáveis em 2012 e 2013, enquanto a competitividade se destacou desfavoravelmente com relação as demais variáveis em todos os anos analisados, evidenciando uma necessidade pela a busca por maior eficiência e produtividade por parte das empresas.

Os resultados também revelaram que a intangibilidade se apresentou mais evidenciada quanto ao seu nível médio, embora não tenha se destacado na liderança em todos os anos da análise, enquanto a governança corporativa manteve-se constante durante todos os anos, mostrando que torna-se necessário a adoção de melhores práticas de governança corporativa por parte das organizações.

Por fim, atendeu-se ao objetivo geral através da aplicação da regressão linear múltipla, ao qual verificou-se que existe uma influência positiva entre a competitividade e a intangibilidade, assim como da governança corporativa com a intangibilidade. Tais resultados, revelam que a inserção das empresas em ambientes altamente competitivos e que primam pela adoção de boas práticas de governança corporativa incitam maiores proporções de ativos intangíveis pelas organizações.

Ademais, os achados evidenciaram também que o tamanho da empresa é uma variável relevante, visto que a partir de determinado tamanho a forma de a empresa crescer é através dos investimentos em recursos intangíveis que serão os fatores chave para a consecução de maior desempenho pelas organizações, visto que os fatores tangíveis têm representatividade limitada.

A pesquisa firmou-se no fato de que há poucos estudos que envolvam a temática, ativos intangíveis e seus influenciadores. Assim, este estudo, contribui com a literatura ao constatar empiricamente, a relevância do poder de competitividade e da adoção de boas práticas de governança corporativa no nível de intangibilidade das empresas, visto que conforme Machado e Kayo (2011), no que tange a governança corporativa, a relação direta desta com os intangíveis seria difícil de ser constatada. Ademais, o estudo confirma ainda o apontado por outros estudos (Albuquerque Filho et al., 2018) quanto ao nível de competitividade como determinante chave na obtenção de maior nível de intangibilidade.

Como recomendações para trabalhos futuros, sugere-se estudar setores diferentes dos abordados nesta pesquisa, bem como, empresas de outros países. Pode-se ainda, utilizar outras técnicas estatísticas para análise dos dados e/ou ainda outro grupo de indicadores. 


\section{REFERÊNCIAS}

Albuquerque Filho, A. R., Ribeiro Macedo, F. F. R., Moura, G. D. D., BrachtFank, D. R., \& Heberle, E. L. (2018). Fatores determinantes da intangibilidade em companhias abertas familiares. Revista de Contabilidade do Mestrado em Ciências Contábeis da UERJ, 23(2), 37-52.

Almeida Ribeiro, J., Gonçalves, C. A., de Souza, G. F. M., Borges, F. R. F., Barakat, L. L., \& Veiga, R. T. (2009). Competências essenciais como fator determinante de competitividade em ambientes hipercompetitivos. REGE. Revista de Gestão, 16(1), 51.

Andrade, A., \& Rossetti, J. P. (2004). Governança corporativa: fundamentos, desenvolvimento e tendências. In Governança corporativa: fundamentos, desenvolvimento e tendências. São Paulo: Atlas.

Appelbaum, S. H., Calla, R., Desautels, D., \&Hasan, L. N. (2017). The challenges of organizational agility: part 2. Industrial and Commercial Training, 49(2), 69-74.

Barajas, A., Shakina, E., \& Fernández-Jardón, C. (2017). Acceleration effect of intangibles in the recovery of corporate performance after-crisis. Research in International Business and Finance, 42, 1115-1122.

Caldeira, A. (2007). Indicadores de competitividade empresarial para a formulação de estratégias. Revista Ibero-Americana de Estratégia, 3(1), 87-100.

Calmanovici, C. E. (2011). A inovação, a competitividade e a projeção mundial das empresas brasileiras. Revista USP, (89), 190-203.

Carvalho, F. de M.; Kayo E. K.; Martin D. M. L. (2010). Tangibilidade e intangibilidade na determinação do desempenho persistente de firmas brasileiras. $R A C$, Curitiba, 14(5), 871-889.

Clausen, S., \& Hirth, S. (2016). Measuring the value of intangibles. Journal of Corporate Finance, 40, 110-127.

Coutinho, L., \& Ferraz, J. C. (1994). Estudo da competitividade da indústria brasileira. Campinas: Papirus.

Darosi, G. C. M. (2014). Governança Corporativa e Desempenho Financeiro nas Sociedades de Energia Elétrica Brasileira. Caderno Profissional de Administração da UNIMEP, 4(2), 29-46.

Decker, F. (2012). Existe relação entre os Ativos Intangíveis e a Rentabilidade das Empresas Listadas no Índice Bovespa?. (Trabalho de Conclusão de Curso, Universidade Federal de Santa Catarina).

Dias de Moura, G., Viana Mecking, D., \& Scarpin, J. E. (2013). Competitividade de mercado, ativos intangíveis e eficiência na combinação dos ativos fixos em companhias abertas listadas na BM\&Fbovespa. Enfoque: Reflexão Contábil, 32(3)

Ferraz, J. C., Kupfer, D., \& Haguenauer, L. (1995). Made in Brazil: desafios competitivos para a indústria. Rio de Janeiro: Campus.

Himmelberg, C. P., Hubbard, R. G., \& Palia, D. (1999). Understanding the determinants of managerial ownership and the link between ownership and performance. Journal of financial economics, 53(3), p. 353-384.

Hinings, C. R., \& Greenwood, R. (1989). The dynamics of strategic change. Oxford: Blackwell Pub.

Kayo, E. K. (2002). A estrutura de capital e o risco das empresas tangível e intangível-intensivas: uma contribuição ao estudo da valoração de empresas (Doctoral dissertation, Universidade de São Paulo).

Keenan, J., \& Aggestam, M. (2001). Corporate governance and intellectual capital: some conceptualisations. Corporate Governance: An International Review, 9(4), 259-275.

Kent, P., \& Stewart, J. (2008). Corporate governance and disclosures on the transition to international financial reporting standards. Accounting\&Finance, 48(4), 649-671.

Kupfer, D., \& Hasenclever, L. (2013). Economia industrial: fundamentos teóricos e práticas no Brasil. Elsevier.

Leite, T. S., \& Santos, D. F. L. (2013). A relação dos ativos intangíveis e o valor de mercado na indústria de materiais básicos do Brasil. Revista Brasileira de Administração Científica, 4(1), 104-121.

Lev, B. (2001). Intangibles: Management, measurement, and reporting. Washington: Brookings Institution Press.

Machado, J. H., \& Famá, R. (2011). Ativos intangíveis e governança corporativa no mercado de capitais brasileiro. Revista Contemporânea de Contabilidade, 8(16).

Marconi, M. D. A., \& Lakatos, E. M. (2011). Técnicas de pesquisa: planejamento e execução de pesquisas, amostragens e técnicas de pesquisa, elaboração, análise e interpretação de dados. São Paulo: Atlas.

Marin, J. K., Liszbinski, B. B., \& Kronbauer, C. A. (2015). Análise do reconhecimento contábil de ativos intangíveis em empresas brasileiras do setor financeiro. Registro Contábil, 6(2), 34-52.

Antunes, M. T. P., \& Martins, E. (2002). Capital intelectual: verdades e mitos. Revista Contabilidade \& Finanças, 13(29), 41-54.

De Andrade, G., \& Theóphilo, C. (2007). Metodologia da investigação científica para Ciências Sociais Aplicadas. São Paulo: Atlas.

Milone, M. C. D. M. (2004). Cálculo do valor de ativos intangíveis: uma metodologia alternativa para a mensuração do valor de marcas (Doctoral dissertation, Universidade de São Paulo). 
Dias de Moura, G., Theiss, S. V., \& Da Cunha, P. R. (2014). Ativos intangíveis e gerenciamento de resultados: uma análise em empresas brasileiras listadas na Bm\&fbovespa. Revista Base (Administração e Contabilidade) da UNISINOS, 11(2).

Dias de Moura, G., Siqueira, P., \& Beuren, I. (2014). Conformidade do disclosure obrigatório dos ativos intangíveis e práticas de governança corporativa. RAM. Revista de Administração Mackenzie, 15(5).

Oliveira, D. D. P. R. D. (2006). Governança corporativa na prática: integrando acionistas, conselho de administração e diretoria executiva na geração de resultados: [conceitos, estruturação, atuação, prática]. São Paulo: Atlas.

Perez, M. M., \& Famá, R. (2015). Características estratégicas dos ativos intangíveis e o desempenho econômico da empresa. Unisanta Law and Social Science, 4(2), 107-123.

Perez, M. M., \& Famá, R. (2006). Ativos intangíveis e o desempenho empresarial. Revista Contabilidade \& Finanças, 17(40), 7-24.

Pires, V. M. (2017). A influência do investimento em recursos intangíveis no desempenho das instituições financeiras estabelecidas no Brasil. (Doctoral dissertation, Universidade do Vale do Rio dos Sinos).

Possas, M. S. (1993). Concorrência e competitividade: notas sobre estratégia e dinâmica seletiva na economia capitalista. (Doctoral dissertation, Universidade Estadual de Campinas).

Richardson, R. J. (1999). Pós-Graduação-Metodologia-Pesquisa Social: Métodos e Técnicas-Métodos Quantitativos e Qualitativos. São Paulo: Atlas.

Richardson, R. J. (1999). Pesquisa social: métodos e técnicas. São Paulo: Atlas.

Rolim, M. V. (2009). Estudo do nível de disclosure dos ativos intangíveis das empresas britânicas pertencentes ao índice FTSE 100. (Master thesis, Universidade Federal de Uberlândia).

Santos, A. G. D. (2009). Comitê de auditoria: uma análise baseada na divulgação das informações de empresas brasileiras (Doctoral dissertation, Universidade de São Paulo).

Schiehll, E., \& Santos, I. O. (2004). Ownership structure and composition of boards of directors: Evidence on Brazilian publicly-traded companies. Revista de Administração, 39(4), 373-384.

Santos, J. L. D., \& Schmidt, P. (2002). Avaliação de ativos intangíveis. São Paulo: Atlas.

Silva, A., Souza, T. R., \& Klann, R. C. (2017). A influência dos ativos intangíveis na relevância da informação contábil. Revista Contemporânea de Contabilidade, 14(31), 26-45.

Silveira, A. D. M. D. (2006). Governança corporativa e estrutura de propriedade: determinantes e relação como desempenho das empresas no Brasil (Doctoral dissertation, Universidade de São Paulo).

Sveiby, K. E. (1998). A nova riqueza das organizações: Gerenciando e avaliando patrimônios de conhecimento. Rio de J aneiro: Campus.

Teixeira, R., Pacheco L.,., Hexsel, A., \&Castagno J unior, R. (2005). Fatores determinantes da competitividade na indústria de telecomunicações e repercussões para a estratégia. Revista Base (Administração e Contabilidade) da UNISINOS, 2(1).

Tsai, C. F., Lu, Y. H., Hung, Y. C., \&Yen, D. C. (2016). Intangible assets evaluation: The machine learning perspective. Neurocomputing, 175, 2016, p. 110-120. 